\title{
Framing culture: VCD music videos and the politics of genre in the Peruvian
} Andes

\section{James Butterworth}

\section{Faculty of Music, University of Oxford, Oxford, UK}

\begin{abstract}
Since the early 2000s Video Compact Discs (VCDs) have come to occupy a prominent position in the Andean musical world and making music videos has become an ordinary and expected activity for many traditional and popular musicians. While the widespread uptake of VCD technology itself occurred with little comment or controversy, the material affordances of this new technology have fuelled contestation about aesthetics, culture and identity. Focusing on the production of santiago music videos in Huancayo, Peru, this article investigates the impact of this technological shift on genre conventions and genre politics. It examines how cultural producers have harnessed, resisted and debated the possibilities of VCD music videos, as well as how genres have been discursively (re)constructed in the process. The article argues that the possibilities afforded by new visual technologies and emerging markets have been a driving force behind recent processes of genre-fication, whether in the service of perpetuating tradition or being part of the next big thing.
\end{abstract}

Keywords: music video, genre, digital technology, folklore, Andes, Peru

\section{Introduction}

At a height of 3,271 metres above sea level, the highland city of Huancayo, in the region of Junín, is six hours by road east of Peru's coastal capital Lima. Several blocks

Contact: James Butterworth james.butterworth@music.ox.ac.uk, Faculty of Music, University of Oxford, St Aldates, Oxford, Oxfordshire OX1 1DB, UK. 
north east of Huancayo's central plaza stands the Plaza Inmaculada, the musical hub of the city. The south side of the plaza is lined by an array of music-disc shops, some tied to small local record labels and stocked with their own original discs and others selling pirate copies of local, national and international music and films. Most discs are VCDs (Video Compact Discs), a relatively low-tech digital format, which, though capable of holding audio-visual material, has a lower storage capacity than a DVD. Since its uptake in the early 2000s VCD technology has become a key part of musical life in the Andes and making music videos has become an ordinary and expected activity for many traditional and popular musicians. VCD technology has also signalled a shift from audio analogue recording to audio-visual digital recording (Stobart 2010, 2011, 2016). In Huancayo, disc shops are kitted out with a television and a VCD player where passersby can try before they buy, sampling the latest releases as well as old classics. The soundtracks of several different VCDs can often be heard booming out simultaneously from different shops, creating a cacophony that echoes the aesthetic of musical competition often found in Andean fiestas (Bigenho 2002: 36; Bigenho and Stobart: forthcoming; Stobart 2006b: 192-8; Turino 1993: 65-7). Dotted between the tightly bunched disc shops are no fewer than three hairdressers, who, not wanting to miss a trick, will happily provide you with a box of pirated music video discs to browse, sample and buy as they trim your locks. ${ }^{1}$

In Huancayo, like in many parts of the world, digital music media has, since the beginning of the twenty-first century, become part of the mediatised soundscape and visual landscape of public space. It is also increasingly enmeshed in commercial activity

\footnotetext{
${ }^{1}$ For discussion of VCD culture elsewhere see Barendregt and Zanten 2002 (Indonesia); Harris 2005 (China's Xinjiang Uyghur Autonomous region); Langlois 2009 (Morocco); Morcom 2008, 2015 (Tibet); Stobart 2010, 2011, 2016 (Bolivia).
} 
as well as accelerating and expanding networks of circulation. Local production of digital music media has been fuelled by the decreasing cost and increasing accessibility of digital technologies, the rising spending power of Andean consumers, and processes of neoliberalisation, which have energised music and media making as an area of entrepreneurial activity (Butterworth 2014). As these shifts have had a broadly democratising effect on access to the means of production (Stobart 2010), music piracy, enabled by the spread of digital technologies, has had similar democratising impacts on circulation and consumption. While there is a danger that such narratives of democratisation can gloss over the transfer of power from social elites to markets (Tucker 2013a), it is clear that these technological and economic shifts afford a host of new musical possibilities.

This article considers how such possibilities are harnessed, resisted and debated by music video producers in Huancayo. Focusing on the production of a traditional regional Andean genre called santiago, I consider the effects of the shift from audio to audio-visual recording on genre conventions and genre politics. How do the construction and policing of genres operate when cultural producers are presented with new technologies, forms of signification and opportunities to engage and mould nascent markets? How are genre boundaries reinforced and how are they transformed?

'Genre' is a term littered throughout ethnomusicological and popular music scholarship. While countless studies focus on single genres, the issue of genre is itself much less often the focal point of research and theorisation. Nonetheless, some broad trends and specific contributions require mention. Over the twentieth century there was a shift away from the approaches of folklorists and comparative musicologists who sought to discover and impose systems of musical classification in ways that mirrored the positivism of the natural sciences (Sparling 2008). In recent decades, by contrast, 
ethnomusicologists and popular music scholars have increasingly stressed the dynamism, flexibility and discursive construction of genre as well as the interdependence of musical aesthetics and ongoing identity work (Gray 2013; Holt 2007; Tuohy 1999; Tucker 2013b).

Aligning music with genre categories is not always an easy task. While much music may conform to the conventions of a single genre there is a vast amount of music that exceeds or creates fusions across genre boundaries. It is also clear that genres are not 'given'. They are culturally constructed and contested sets of aesthetic conventions and ethical orientations that emerge and converge at particular historical moments and particular places, modulating as they travel through time and space. While the concept of genre has shifted from its origins in Ancient Greece, through eighteenth-century European notions of autonomous art, to the present day, musical genre has, since the first half of the twentieth century, had a profound relationship with commercial recording production (Frith 1998; Negus 1999). Blues (Keil 1966), salsa (Manuel 1991) and 'world music' (cf. Frith 1998: 85; Taylor 1997) are some of the most salient examples of genres that coalesced as much through the activities of record producers and marketers as through groups of musicians or audiences.

In Peru, the tasks of naming, defining and identifying musical genres can be extremely challenging. Huayno, for example, the most widespread Andean music genre, is a single genre moniker that encompasses dozens of distinct styles, ensemble types and performance contexts that may sound completely different and/or embody opposing ideological orientations (see Tucker 2013b: 35-78). Furthermore, much musical performance fuses different genres. Sometimes this is self-conscious, such as in the case of chicha in the 1980s, which purposefully combined Colombian cumbia, Andean huayno and rock music, experimenting with proportions of these ingredients ever since 
(Romero 2002; Tucker 2013c). One also encounters words like ahuaynada ('huayno-ed' or 'huayno-ifed'), which turns huayno from a noun into a past participle, indicating the potential for genres to be put to use as dynamic cultural agents that can be applied as tools of aesthetic and ethical transformation; as Sue Tuohy writes, 'genres are categories with power and utility' (1999: 40).

My primary focus in this article is santiago music. Whereas huayno and cumbia are national and international genres respectively, principally sustained by publics dispersed across vast geographical areas and connected through mass-mediated texts, santiago is distinctly regional. While it has its own mass-mediated texts, santiago is largely limited by the spatial boundaries of el centro (the centre), a loosely-defined area of the Peruvian Andes spanning the provinces of Huánuco, Junín and Huancavelica (and to some extent Ayacucho). Santiago VCDs undoubtedly circulate through migrant networks linking the central Andes and the coastal capital, Lima, but only occasionally is santiago performed or listened to by people from other regions of the Peruvian Andes and virtually not at all by those who lack or disavow their Andean heritage. ${ }^{2}$

I begin by discussing the roots of santiago music in a centuries-old animal fertility ritual and its more recent development as a stand-alone mass-mediated regional genre. I chart how the music video has become the dominant medium for santiago and the VCD disc its dominant format, highlighting how visual technology has impacted the musical life and soundscape of Huancayo. Focusing on a single record label, Producciones Ramos, I discuss how cultural producers have harnessed the signifying

\footnotetext{
${ }^{2}$ Music, often more so than other cultural domains, has long been an important source of Andean identity for migrants moving from the highlands to Lima and other coastal cities (see Romero 2001; Tucker 2013b; Turino 1993). Folkloric artists from the northern and southern Andes do perform santiago from time to time but it is rarely part of their core repertoire.
} 
power of the audio-visual domain and the way in which generic conventions have been established, contested and policed in the process. Within these genre politics producers are variously motivated by their desires to represent costumbre ('custom') and to produce entertainment oriented towards the latest trends and fashions. Cutting across these competing motivations, the article points to the role of market forces and new visual technologies in process of genre-fication, where heterogeneous and fluid practices are reified, whether in service of perpetuating tradition or being part of the 'next big thing'.

\section{Ritual to record: santiago's transformation}

Santiago music derives from a ritual of the same name that is often more specifically referred to as la herranza (literally, 'the branding') and takes place across the central Peruvian Andes in late July. Practiced in rural areas, this sacred ritual is believed by participants to protect the health, and enhance the fertility, of local livestock for the coming year. The herranza is traditionally composed of several phases comprising offerings, games, prediction rites, music, dance and singing; these phases lead ultimately to the central act of branding animals (usually cattle), typically on 25 July. Historically, there was a strong association between the herranza and an indigenous deity known as wamani (roughly, 'mountain god') who was both feared and revered for his power to affect the fertility of livestock and land (Romero 2001: 36-7). However, because the Catholic celebration of Saint Santiago took place at the same time of year as the herranza and because of the similarities in terms of characteristics of wamani and Saint Santiago, the two sacred monikers have come to stand for 'a single supreme being: wamani or Santiago’ (Romero 1999: 168). 
Music plays a key role throughout all stages of the herranza; the music performed is inextricably related to the organisation of the ritual. In Huancayo and the wider Junín region, the principal melody instrument has traditionally been a spiralshaped horn trumpet known as a wakrapuku (Quechua) or cacho (Spanish), which can either be played solo or as a pair, predominantly playing a third apart. To the south, in the region of Huancavelica, a long, straight cane trumpet called a yungur (also loncor) typically replaced the wakrapuku. In recent years, however, the yungur has also increasingly been favoured over the wakrapuku in Junín and features in the majority of santiago music videos, which many of my interlocutors attributed to its fuller and louder sound. The principal melody instrument is normally joined by a violin and one or more female singers, who often double as performers of the small hand-held tinya drum. Beyond instrumentation, music of the herranza typically possesses indigenous musical traits such as the use of Quechua lyrics (instead of or in addition to Spanish), highpitched female voices, regular rhythms that avoid syncopation, and use of the natural harmonic series produced by the wakrapuku and yungur. The herranza is cast by participants as one of the strongest surviving autochthonous customs of the region. The fact that many of the elements that now often make up the ritual (cows, horses, donkeys, violins, and Saint Santiago among others) were only introduced to the Andes during the Spanish colonial period, exemplifies a process of indigenisation where external elements have been incorporated and appropriated for the purposes of indigenous cultural renewal (Stobart 2006b: 86).

Raúl Romero's ethnographic accounts from the 1980s and 1990s describe herranza music in Junín as existing firmly in the 'private' domain, which, he claims, appeared 'to be reserved for maintaining continuities with a rural "past"'. The music of orquestas típicas and nationally disseminated styles such as huayno and chicha, on the 
other hand, he argues, resided in the 'public' domain, which appeared 'to be the space for negotiating modernity' (Romero 2001: 35$){ }^{3}$ Romero concludes:

No one wants to change, innovate, or experiment with herranza music; nor does anyone want to introduce new, 'modern' instruments to its customary ensemble. Its seasonal character works as an additional 'protective' shield against manipulation, and so does the fact that professionalization is not a feasible alternative here. (ibid: 63)

There is a case to be made that Romero overstates the extent of separation between the private and the public, as well as the traditional and the modern. Furthermore, Romero does not mention recordings of santiago music but I have found evidence of commercial santiago recordings from Junín dating from at least the 1970s and artists from Ayacucho had recorded classical guitar arrangements of santiago by at least the 1980s. ${ }^{4}$ In 2012 I visited and interviewed a veteran singer of santiago and huayno from Junín, Benigno Montes Alveres, who showed me around a dozen vinyl discs that he had recorded during the 1970s and 1980s. Many of these discs included santiago songs, the earliest of which was a recording of a song called 'Flor Moradita' ('Little Purple Flower'), recorded on a label called Estrella Record, which he dated approximately to 1976. The reach of these recordings and the contexts in which they were consumed (during or outside the herranza) is not entirely clear but a number of people told me that

\footnotetext{
${ }^{3}$ Orquestas típicas are ensembles associated with the central Peruvian Andes and are made up of several or more saxophones, a couple of clarinets, a violin and a harp. They regularly feature in festivals and processions throughout the region and perform in a wide range of styles (see Romero 2001).

${ }^{4}$ For example, a santiago called 'Toril' appears on the 1988 album Peru-Guitara by the Ayacuchan guitarist Raúl García Zárate.
} 
the seasonal associations of santiago remained strong during this period and recordings tended to be released and played to coincide with the festival. These accounts challenge Romero's depiction of santiago music as standing apart from processes of modernisation. Notwithstanding, much has changed in the region since the 1980s and early 1990s when much of Romero's fieldwork was conducted. Driven by recording technology and the capitalisation of culture, santiago has evolved to become a standalone mass-mediated genre that exists largely independently of the herranza ritual and now has a prominent role in the Huancayo soundscape. Today, while there is an intensification of production and consumption around June, July and August, it is now hard to escape from the sounds and moving images of santiago recordings booming out from television sets in shops, through the streets, and across the plazas in and around the city throughout the year. It appears this calendrical shift occurred alongside the introduction of VCD technology in the early 2000s, since which time there has been an explosion in the production of santiago music videos. This is testament to the fact that visual technology, perhaps counterintuitively, has acted on musical life in Huancayo in soundscape-changing ways.

One of several music video production companies established in Huancayo during this period is the family-run Producciones Ramos (Ramos Productions), which produce music videos of regional styles, such as santiago and orquestas típicas, as well as the nationally circulating huayno. The label is operated by husband and wife Antonio and Rosario Ramos, and their son Lenin. Before establishing the production company, Antonio had worked since the 1970s with folkloric performers across the whole of Peru, organising live performance events and recording musicians on LPs and cassettes. If Antonio provided the experience and knowledge about local music and folklore, it was his son, Lenin, who provided the technical knowhow and creative energy, particularly in 
relation to digital technology and audio-visual media. ${ }^{5}$ He had spent three years studying in Lima at Charles Chaplin, an institute offering training in audio and visual technology. Returning to Huancayo in 2005 , in his early twenties, he joined the family business and began producing VCD music videos. The label's operations have been almost entirely based in Huancayo, seemingly unlike many other 'Huancayo-based' labels, which often split their operations between Huancayo and Lima with some only travelling to Huancayo for filming. Although still operating on a reasonably small scale, Producciones Ramos is different from a number of other labels at which all the work is done by one person (see Langlois 2009; Stobart 2011). Producciones Ramos, by contrast, is a family run company with a relatively well-resourced studio, employing two or three other people on an ad hoc basis to contribute to the production and editing process. During my first visit in 2010 one of these employees was Judith Apari who was in her mid-twenties, worked five or six days a week as a video editor and in her spare time worked as a local huayno singer.

Like most music video labels in Peru (and the Andes in general), Producciones Ramos is unable to rely on significant income from the distribution of music discs because of high levels of piracy, which nationally have been estimated to be $98 \%$ (IIPA 2010). However, conversations with my interlocutors as well my own observations, suggest that levels of piracy for regional genres such as santiago are lower than this, due to the smaller scale of the marketplace and the greater propensity for artists to distribute their own VCDs directly. That said, the principal business model for music video labels is to charge artists a relatively large one-off fee. During my research in 2010 the charge to an artist or group for producing a santiago VCD album was in the

\footnotetext{
${ }^{5}$ Stobart (2016) observes a strikingly similar family dynamic and division of expertise at CG Records in Cochabamba, Bolivia.
} 
region of US\$ 350-450, which included one full day of filming and the whole editing process but did not include the cost of any additional studio musicians. Larger-scale productions that included two or three days of filming could easily push the costs up to around US\$1,000, not including the cost of polleras (Andean skirts), which may as much as double the cost of the production for the artist(s). These are significant investments but ones that have quickly become seen as integral to the practice of being a musician in the Andes (Stobart 2016).

In the sections that follow I draw on participant observation and interviews conducted over the course of several intensive visits to Producciones Ramos between 2010 and 2012.

\section{The VCD production process}

The shift from audio to audio-visual recording in the Andes has profoundly influenced the development of musical forms, practices and contexts. However, visual-semiotic developments attached to this technological shift build on a longer history of visual mediation in Andean music. Costuming, in particular, has been an important visual signifier of place, genre and authenticity, from the estudiantina ensembles of the $1920 \mathrm{~s}$ and 1930s, through the state certification of folkloric performers, most notably between the 1940s and 1980s (see Romero 2001: 97-102), to the marketing of huayno music in the latter half of the twentieth century through promotional materials and album covers. Today, like other music video labels, Producciones Ramos combines new and existing sets of visual signs and symbols in extending the technological mediation of genres beyond musical sound. Notwithstanding significant diversity and inter-genre influence, a santiago music video would normally be identifiable based on the visuals alone. The strength of signification, I suggest, becomes enhanced in the visual domain, which 
seems to provide a deeper capacity for carrying indexical and iconic signs of particular genres and contexts than is possible through purely audio recordings (see also Holt 2007: 5). While my research has focused on VCD production rather than reception, my experience of watching music videos with my interlocutors suggests that listenerviewers are more likely to comment on visual rather than sonic aspects. As such, it appears that the capacity for visual signification has been an important factor in the explosion in music video production and consumption in the Andes and the associated politics of genre.

A VCD album typically features between ten and twenty tracks. The first stage of production is usually to record the audio track, which at Producciones Ramos is often recorded 'live' in the studio, though sometimes musicians are recorded individually and then the producer will assemble the parts. Depending on the budget of the performer(s) who have commissioned the VCD, the filming process may last between one and several days. Filming takes place 'on location' (i.e. not in studio conditions) and while some shots may be captured close to the studio, the majority of filming takes place in towns, villages and the countryside outside Huancayo, which can involve drives of a few hours. ${ }^{6}$ Particular locations may be chosen because of their general symbolism, their beauty or their personal relevance to the performers. In addition to the iconic use of moving images featuring musical instruments, visual shots of particular animals, plants, flowers, landscapes, geological features, landmarks, clothes, textiles and dancing may be chosen for their capacity to signify particular genres and contexts. In the case of santiago, such images may already have a strong association with the original ritual context.

\footnotetext{
${ }^{6}$ In Huancayo, I have not encountered the use of green screen technology, as discussed by Stobart (2011) in relation to Bolivian music videos.
} 
The majority of filming involves capturing purely visual material, which is afterwards synced with the studio audio recording. During the filming process, the prerecorded audio is usually played through a portable speaker, allowing the performers to mime and/or dance in sync. There is rarely any particular concern, however, with seamless synchronisation and there are regularly small but noticeable discrepancies between the audio and the visual performances. At Producciones Ramos, filming is usually a two-camera operation, though sometimes only one camera is used if the budget is particularly tight. During my research, the label's main camera was a Sony HDR-FX1, bought second hand in the capital Lima, for in the region of US $\$ 3,000{ }^{7}$ This is a (semi-)professional tape-based camera that records in full HD 1080 resolution, though given the compression involved in burning to a VCD, this capability is never realised in the final product. $^{8}$

At Producciones Ramos, santiago tracks are normally filmed at least twice, using different locations and/or costumes, so as to have a minimum of four video streams (two from each camera) to choose from in the editing process. However, many higher budget videos, especially huayno, involve several takes and a dozen or so streams. The editing process begins by importing all the raw footage to a computer and assigning each stream to an individual channel in the video editing software (Adobe

\footnotetext{
${ }^{7}$ This is same camera used by CG Records in Cochabamba, Bolivia, and discussed by Stobart (2016).

${ }^{8}$ While consumers rarely experience videos in high definition, labels regularly boast about the high-definition capabilities and even when videos are uploaded to YouTube and similar sites they tend to use much lower resolutions than high definition. However, technological access is continually changing and over the last five years I have been aware of more and more highdefinition folkloric music videos uploaded to YouTube.
} 
Premier Pro). Typically, clips are made to alternate in parallel with the divisions between melodic phrases, an example of the subordination of moving images to the musical structures typical of music videos (Cook 2000). This allows the editor to watch all the different streams for each melodic phrase, decide which is the best version, and then place the selected clip into the 'master' channel. What constituted the 'best' moving image was contingent on several factors, including what was expected of the genre, what was considered costumbre ('custom'), what was visually pleasing and what best mirrored the music and lyrics, as well as the images that preceded and followed. While I often encountered a concern that the lyrics, music and visuals should correspond with each other, in the sense of word painting, there was rarely an interest in developing any explicit or coherent narrative. As Carol Vernallis has suggested, narrative in the music-video image is rarely as developed and embodied as it is in film because otherwise 'videomakers would run the risk of our becoming so engaged with the actions of the characters or concerned with impending events that we are pulled outside the realm of the video' (2004: 4).

\section{Mediating genre audio-visually}

In the case of santiago music videos, one of the main concerns at Producciones Ramos was to illustrate costumbre. In some contexts, costumbre can have a similar meaning to 'custom' (i.e. a tradition or habitual practice) but its local connotations often include a reified notion of pure and authentic culture. In his research among the Chayantaka in Bolivia, Thomas Solomon interprets the word costumbre as deeply related to ideas of inheritance, place, and identity; he views the repeated use of this word in indigenous songs as a meta-cultural discourse that helps to constitute local knowledge (1997: 3292). Most notably, the use of the term costumbre among people at Producciones Ramos 
was restricted to discourse surrounding santiago and generally was not used to describe huayno for reasons that I expand upon in the next section.

One of the defining images of a santiago music video is the singer(s), who is typically female and known as a santiaguera. Beyond her singing, a santiaguera is characterised by her distinctive dress (see figure 1), which usually includes a pollera (colourful embroidered Andean skirt), a blouse, a coloured hat, a llicla (patterned shawl) and a faja (patterned belt). In addition, singers may adorn themselves with a miniature tinya drum attached to their waist and hualljas (also wallqa: strings of fruit and bread that in the herranza is presented as an offering to wamani/Saint Santiago) hanging from their neck. To create visual variety santiagueras may alternate between different sets of clothes during the filming, but this is heavily dependent on budget: a handcrafted pollera can cost several hundred dollars so aesthetic variation is also a symbol of investment, wealth and prestige (see also Van Vleet 2008: 123-6). The figure of the santiaguera also features in music videos in the form of santiaguera statues found throughout villages and towns in the central Andes and often used as a backdrop for music video performances.

\section{[INSERT FIGURE 1 HERE]}

Santiago music videos are almost always filmed outside. While it is not unusual for sequences to be shot in village and town plazas, the majority of the footage is set in rural locations that foreground the natural and agricultural environment, including mountains, fields, crops, lakes, rivers (figure 2) and waterfalls. ${ }^{9}$ The importance of these is by no means restricted to santiago; waterfalls and rivers, for example, are associated across the Andes with ideas of productivity, especially in relation to sound and music

\footnotetext{
${ }^{9}$ For discussion of the importance of landscape in music videos see Morcom (2015, for Tibet) and Stobart (2016, for Bolivia).
} 
(Stobart 2006a, 2006b: 244; Turino 1983), as well as being liminal places that mediate between the land of the living and the underworld of the ancestors (Solomon 1997: 248-9).

[INSERT FIGURE 2 HERE]

Shots of specific flora and fauna are important, too. Most santiago VCDs feature shots of animals, particularly cows, due to their centrality in the ritual, though shots of sheep are also common. While such shots may be used as B-roll, producers were often keen to secure footage of animals and performers in shot together. This sometimes presents santiagueras with the particularly challenging task of singing to camera while milking a cow, which is often recognised as a humorous situation both in filming and watching the video.

A particular plant often associated with santiago is the limalima flower, typically used to adorn people's hats during the Santiago festival (Ortiz Rescaniere 2001: 242). While many people I spoke with were aware of the association between the limalima and santiago, few were able to explain why the two were linked. According to Gutiérrez Santayana, however, a nickname for the limalima is 'la hablardora' ('the chatterbox') because it is believed to give people 'the power to speak at the moment of counting one's cattle in front of the patron [santiago]' (1992: 71). Beyond the perceived beauty of the limalima's form and deep red colour, people often linked the flower's value with the fact that it is notoriously difficult to find, as it tends to grow at high altitude and such spots can often be several hours walk from the nearest road. ${ }^{10}$

I first encountered a limalima flower on my first visit to the Producciones Ramos studio, where I was handed a flower that had been picked and used in a shoot

\footnotetext{
${ }^{10}$ One botanical report records the limalima having been found at 4400 and 4700 metres (Yarupaitán Galván and Albán Castillo 2004).
} 
two days previously and had since been kept in a jar of water. Lenin Ramos proudly recounted the impossibly steep hike he had undertaken to find the flower while lugging much of the production equipment with him. Those working at Producciones Ramos regularly boasted of their willingness to travel in order to find the best images. Beyond the beauty and symbolism of the limalima, the effort involved in locating it appeared to imbue the production with greater value. To an extent, the notion of travelling in order to locate the best images was a self-fulfilling prophecy in that the very act of travelling — and the effort involved — generated value, highlighting the interrelation of ethics and aesthetics in music video.

Because of the importance that the producers attached to this particular limalima, I assumed that the limalima was an essential ingredient of a santiago VCD. However, though the limalima continued as a trope for authenticity throughout my visits I have seen the flower featured in only a couple of the dozens of videos I have watched produced by Producciones Ramos and in a handful of other santiago VCDs produced by other labels. As such, it is striking that an image that has such power to convey genre identity can be something that is exceptional rather than conventional.

\section{Folklore, fashion and genre policing}

In the previous section I focused on the kinds of images that most people agreed were either 'core' (such as santiago clothing and livestock) or specifically relevant to santiago (such as the limalima flower). However, many aspects of santiago music videos foster less agreement and trigger debates about the limits of what is acceptable and what should be excluded. In my experience, producers tended to be more concerned than singers and musicians with this kind of genre policing. The producers' concerns typically involved protecting santiago's identity as costumbre and preventing the 
excessive bleeding of signs and symbols from other folkloric and popular genres, particularly huayno and cumbia. While the producers' discourse invoked familiar tropes about maintaining the 'traditional' and the 'authentic' in the face of the 'modern', it is clear that that santiago genre politics exceed these concerns. Producers, I suggest, are also concerned with the integrity and congruity of genres for aesthetic as well as commercial reasons.

During my research, it became clear that santiago could be categorised as both costumbre and folclor. The noun folclor (folklore) and the adjective folcolórico/a (folkloric) are inescapable in the context of Andean music making. Folclor tends to be a catchall term, frequently invoked in the context of music and culture that is imbued with time-depth and seen as in some way representative of a people or a place. However, huayno, in contrast to santiago, was considered folklor but not costumbre. Huayno, the most widespread Andean genre, tends to be a secular, recreational genre and, particularly in its commercial form, is dominated by sentimental narratives of love gone sour (Butterworth 2017; Tucker 2013a). In the minds of the producers, the sentimental content of huayno was a key factor in its separation from costumbre, which they considered to be more earnest in character. ${ }^{11}$ Lenin explained:

It's really important to see the changes, how can I put it, the varying of the genre... there are people using other types of instruments, they are changing [the genre], and at times, at the label we don't like to exaggerate these changes because people don't accept them, well, the majority. People of the same town or same place [as a genre] don't accept other types of instruments that aren't traditional. It's the same if the artist, for

\footnotetext{
${ }^{11}$ Such taxonomies are not universally applicable as in other contexts and geographical locations forms of huayno are perceived to be costumbre.
} 
instance, is very modern, you know, and doesn't reflect la costumbre in the video's meaning ... [It's important that a production] always appreciates the origins of the music, the lyrics, and la costumbre, most of all in music videos of costumbre, like santiago, like huaylas, you know. Santiago is music for the animals; it's not about love or anything like that. (Lenin Ramos, interview, Huancayo, 15 May 2010)

From Lenin's comments emerge the strong interrelation of genre and place as well as a notion about consumers and audiences driving aesthetic conventions. While change in 'traditional' music settings is often discursively associated with commercialisation, here it is striking that Lenin suggests that market forces can act as a brake on cultural change. The phrase 'santiago is music for the animals; it's not about love or anything like that' draws a comparison between santiago and huayno, which, though still classed as folclor is perceived as more commercial and sentimental, as well as less geographically specific.

While santiago is dominated by rural imagery, huayno is strongly associated with urbanising Andean migrants and, as such, its imagery spans nostalgic depictions of rural Andean roots and 'realist' portrayals of contemporary domestic urban life. Musically, most commercial huayno features electric bass, drum machines, timbales and often keyboard, a type of orchestration that would rarely be considered conventional for santiago, despite being increasingly common; thus, such genre distinctions are constantly under pressure and theory is often disrupted in practice. Another common difference between santiago and huayno videos is the rate at which shots alternate and the amount of camera movement in each shot. Santiago videos tend to feature more static shots, gentle zooms, and changes of shot only every several seconds. In huayno videos, however, it is acceptable for shots to alternate more quickly; some huayno 
videos can flash between several shots in a matter of seconds, particularly during percussion fills. Furthermore, the huayno visual aesthetic may include close-up profile shots, more aggressive zoom shots and manual camera movement. These aesthetic differences point to the fact that santiago music videos tend to be oriented more toward the aim of folkloric representation compared to huayno music videos, which are more likely to be orientated toward popular entertainment. However, this divergent framing of music videos as forms of representation and entertainment, I suggest, is also relevant to aesthetic debates within the santiago genre in its own right, a point to which I return below.

The tensions between documenting and maintaining costumbre, following fashions and creating commercial entertainment are also played out in discourses related to santiago's lyrical transformations. Historically, the lyrics of many santiago songs have been about animals, nature and local places and, symbolically, have been connected to the herranza ritual. While such lyrics can still be found in contemporary santiago music videos, today the majority of lyrics concern romantic disappointment and breakdown. Discourse surrounding this shift was pervasive among my interlocutors and I regularly encountered ambivalent narratives that claimed such sentimental themes were not theoretically or authentically part of the santiago genre. On one occasion, I interviewed a young santiago singer called Rosmery Perez Inocente, who appeared frank and unashamed about this development: 'before, adults sang just about dedicating yourself to your animals, about your village, about how your village was getting on, but now the singers that are coming through sing about love, about suffering' (interview, Huancayo, 28 June 2012). When I conducted this interview at the Producciones Ramos studio, Lenin was in earshot and caught my eye with a look of rueful exasperation, echoing his statement that 'santiago is music for the animals; it's not about love or 
anything like that'. The theme of suffering spans many Andean songs going back centuries, but in livestock-related songs such as santiago, suffering has often been connected with the labour and loneliness of shepherding and herding in the mountains. However, Lenin's comment implies that suffering as it pertains to love and sentimentality should be restricted principally to the domain of huayno music.

Judith Apari, a singer and video editor who worked at Producciones Ramos during my early visits, similarly told me:

Santiago is mostly about paying homage to your animals, and to patron Santiago, but these days there are many singers who are not aware of what folklore is. They release tracks to [entertain], but not for the animals, not to sing 'My cow is so lovely'... they release songs about jealously or fighting. You see, they are young and it's meaningless music in some cases, something crude. It might be someone who is misguided, or who doesn’t have a good producer. (Judith Apari, interview, Huancayo, 19 May 2010)

When Judith talks about songs of jealousy and fighting, she implies that this is something that happens between lovers. However, her description of this as crude or meaningless was striking, as she was herself also a huayno singer who regularly sang about these themes. Her uneasiness cannot simply be attributed to a perceived loss of tradition; the issue of maintaining genre boundaries is essential here, too, as producers and performers negotiate influences from a media-saturated environment. Moreover, the insistence on santiago's purity of intent discursively erases a history of santiagos containing bawdy and humorous sexual double entendre, typical of Quechua-language forms, which have also been performed during festivities surrounding the herranza. 
While these songs do not match the sentimentality and directness of many contemporary santiago music videos their existence casts efforts by producers to define and delimit genres and their histories as somewhat laboured. Notwithstanding rueful narratives around santiago lyrics and attempts to safeguard costumbre, producers are aware that incorporating huayno's lyrics of bad romance, or, for example, referencing cumbia's more Latin rhythms and sexier moves, can be a key part of creating popular entertainment that will find a particular foothold in the marketplace. Lenin explained: The producer suggests things to new artists because of his experience. But the producer must also be open to new ideas, for sure ... Now people are using electronic drum machines; ok, it's good to dance to, but only at a low level in the mix: it should be limited, not exaggerated. So in discussions between the artist and the producer I think it's possible to come to an agreement ... But when they come out with mediocre ideas, you know, it wouldn't be the first time, there are things they say at times like 'film me wearing this top' in a santiago video, or 'I'm going to dance scandalously'. But it's not part of the custom, and this is what the producer has to say ... There are also artists that know and accept la costumbre and I think that [Producciones] Ramos has something—something that other labels don't have - and that is contact with people who do know about this [costumbre]. (Lenin Ramos, interview, Huancayo, 15 May 2010)

Lenin's comments suggest that maintaining costumbre is not just about what should be included, but also about what should be excluded from the audio-visual aesthetic. For example, the wearing of a 'top' (a word which connotes a piece of clothing derived from Western fashion rather than traditional dress) as well as dancing 'scandalously' 
(which refers to the more erotic dance styles associated with genres such cumbia, salsa, and, to a certain extent, huayno) are perceived to be inappropriate. Crucially, however, they are generically inappropriate rather than inappropriate in and of themselves as, in el centro, there is substantial overlap in audiences for santiago, huayno and cumbia and all three feature in VCDs produced by the Ramos label.

These genre politics also extend to making sure that symbols specific to santiago do not make their way into huayno videos. For example, many of the plazas and parks in el centro contain sculptures of santiago performers and musical instruments associated with santiago such as violins, wakarapukus, and tinyas. During the filming of two huayno videos in two such locations (El Parque de la Identidad Wanka and El Parque Turístico de los Sombreros) I witnessed Lenin trying to avoid these sculptures when framing shots. On one occasion, a singer took up a position beneath a towering santiaguera figure because she thought it was attractive but Lenin suggested that it was inappropriate, saying 'no, this is not santiago!' Because these sculptures were explicit visual symbols of santiago they were considered to be outside of the huayno genre. Moreover, the exclusion of these images in huayno served to protect and reify them as santiago symbols used only for costumbre.

While the notion of a tradition-modernity continuum carries less and less currency within social-scientific inquiry it remains a prism through which many in the Andes continue to experience and interpret social and cultural change. However, its apparent applicability in the situations mentioned above should not blind us to what else may be going on. As such, it would be an oversimplification to summarise Lenin's comments as fuelled by a rigidly conservative orientation towards protecting the traditional from the modern. I argue that the issue of genre is vitally important too, here bound up with market positioning and the harnessing of new visual technologies. 
Lenin's comments can be interpreted as conveying his awareness of the need as a producer to maintain genre distinctions in a media-saturated environment. Moreover, although he talks about maintaining costumbre, Lenin is well aware that fashionable tops and scandalous dancing are often part of making a popular and entertaining product — including many of the santiago videos produced by Producciones Ramos.

\section{Framing culture and genre-fication}

Stefan Fiol (2010), writing about VCD music videos of Himalayan possession rituals, argues that viewers simultaneously experience VCDs as ritual performances and media performances. He resists ideological assumptions of modernity that view these as separate and opposing domains, instead stressing the 'increased interpenetration of ritual and media in social life' (29). Such a reading is consistent with many musical and cultural practices in the Andes, including santiago. While santiago may now be produced and consumed as a stand-alone genre by those who do not participate in the herranza ritual, this certainly does not preclude santiago media being part of the ritual proper, nor people attributing ritual significance to santiago VCDs. For example, the first time I encountered a santiago VCD was when a musician at a herranza ritual in Junín handed me a copy of his groups' santiago album (the effect of VCD culture on ritual practices surrounding the herranza certainly requires further ethnographic investigation). However, clear distinctions emerge from the transformation of santiago as music from a private seasonal ritual to a cultural form that circulates in a massmediated public sphere and drives a great deal of commercial activity all year round. Lenin explained, perhaps with a touch of hyperbole:

Here in the city, the festival of Santiago is synonymous with partying, nothing else. People have Santiago celebrations for their own benefit, for a 
business, they contract artists who sing santiago party music [fiesta de santiago], not santiago, but santiago party music, with all those lyrics about love... And the festival of Santiago on the $24^{\text {th }}$, instead of the custom you conducted with the animals until dawn, now it's all about business. It's all about selling beer, partying ...they don't go in search of their cattle but go in search of the parties, the best artists and drinking all night long. (Lenin Ramos, interview, Huancayo, 29 June 2012)

Here, however, my interest is less in the dual framing of VCDs as ritual and media than in the dual framing of santiago media itself as an act of folkloric representation, on the one hand, and as a mode of popular entertainment, on the other. In distinguishing between the aims of folkloric representation and popular entertainment I do not imply that these relate to two mutually exclusive groups of people or groups of videos. Rather, this dual framing shines a light on the different motivations behind santiago music video production. As a form of folkloric representation, santiago music videos can be understood as a means of affirming a distinct regional identity and cultural heritage, as typified by Lenin's suggestion that people from the same town or place as a particular genre may object to it undergoing any substantial change. Such notions rely on the idea that 'culture sits in places' (Escobar 2001) and coincide with philosophies of folklorisation (Mendoza 2008: esp. 6-7), in which aesthetic practices become standardised and formally recognised as representative of particular places and groups. Framing culture in this way has a kind of documentary purpose.

However, santiago music video production is also driven by the desire to create and consume popular entertainment, involving a greater emphasis on fun, fashion and cosmopolitanism, as well as a more expansive form of identification and public 
intimacy. The term 'entertainment' does not imply triviality here. As Peter Stromberg asserts, 'entertainment and the pleasure it generates are fundamental to our vision of the good life' and the social reproduction of 'ideas, practices, and values' (2009: 8). While the frame of popular entertainment may carry more overt commercial overtones, this is not a simple distinction between commodified and instrumentalised culture, on the one hand, and autonomous and uncorrupted culture, on the other; there is a market for tradition, too. Both folkloric representation and popular entertainment are consistent with George Yudice's notion of 'culture as resource' (2003); they both imply the expedient use and potential marketisation of culture, but for different ends. The differential emphasis on representing and entertaining, I suggest, is critical to accounting for variation of aesthetic ideals both within santiago music videos and between santiago and other genres.

However, these divergent motivations and ideals are also connected through a preoccupation with genre and processes of genre-fication. In many respects, these genre politics are similar to those of other times and places. For example, during the development of the huayno recording industry in the 1950s and 1960s, regional huayno styles were stereotyped and stabilised to form quasi-generic categories where new regional variants came to the fore as the market for previously-fashionable styles became saturated (see Turino 1988). This process has been replicated since the early 2000s in the huayno pop boom, in which 'northern huayno' (with harp), popularised by artists such as Dina Páucar and Sonia Morales, has given way to the huayno of artists from the Cuzco region (with requinto or bandurria), such as Chinito del Ande and Rosita de Espinar, and, since the early 2010s, to 'southern huayno' (with teclado, a distinctive keyboard sound) associated with artists from Peru's border with Bolivia, such as Yobana Hancco and Yarita Lizeth Yanarico. Thus, taking a local practice, 
defining it as a distinctive tradition, and seeking to consolidate a market for it has been familiar feature of the huayno industry for decades. However, VCD technology has enabled processes of mediatisation, market differentiation and folklorisation to spread beyond the huayno industry to regional styles such as santiago. Yet, while producers have harnessed this new visual technology to consolidate santiago as a distinctive and bounded genre that is distinct from huayno (and cumbia), the parallels in the audiovisual medium stretch such distinctions and boundaries to the limits by facilitating the circulation and cross-fertilisation of sonic, lyrical and visual signifiers.

\section{Conclusion}

As part of a shift from analogue to digital technology, VCDs have emerged as a central feature of much Andean music making; as well as shifting the balance away from audio recording toward audio-visual recording they have energised musical life in soundscape-changing ways. These changes have been influenced by increasing access to, and affordability of, technology, alongside the rise of small-scale enterprise surrounding music performance, production and circulation. In the context of folkloric music in Huancayo, I detect no concern about the pervasiveness of VCD technology nor the speed with which it has become an integral part of musical and social life. However, while the use of VCD technology in and of itself may be relatively unproblematic for musicians, mediators and audiences in el centro, there is much debate among cultural producers about how it is used and to what ends. Building on earlier practices of differentiation and visual signification in Andean music, VCD technology has enabled and energised new forms of signifying folklore, costumbre and local (indigenous) identity. It has fuelled processes of genre-fication in which santiago has been consolidated as a distinct and bounded genre while also bringing it into dialogue with 
other genres and markets beyond el centro. However, the message is not simply prescribed by the medium: aesthetics matter, too, and I have suggested that attending to the divergent aims of representation and entertainment provides a useful way of understanding what is at stake in santiago music video production. I have also demonstrated that while familiar tropes of 'authenticity' and 'tradition' provide some insight into the discourses and practices surrounding santiago music video production, there is much more going on besides. Processes of genre-fication cut across these familiar tropes and, whether concerned with representing local costumbre or capitalising on the latest national trends, producers have harnessed the signifying potential of the visual domain to consolidate musical genres and markets.

\section{Acknowledgements}

I am extremely grateful to the musicians and producers that gave up their time to talk to me as part of this research. Special thanks go to Antonio, Rosario and Lenin Ramos of Producciones Ramos. I wish to thank Henry Stobart for his support and sage advice at various stages of the research as well as Chloe Alaghband-Zadeh for her comments on an earlier version of this article. I also gratefully acknowledge the support of the UK Arts and Humanities Research Council.

\section{Funding}

This work was supported by the Arts and Humanities Research Council.

\section{Note on contributor}


James Butterworth is a British Academy Postdoctoral Fellow in the Faculty of Music at the University of Oxford and was previously a Postdoctoral Research Associate on the UK Arts and Humanities Research Council funded project Performing hip hop Englishness at the University of Cambridge. He completed his PhD in Ethnomusicology at Royal Holloway University of London in 2014. His research focuses on popular and folkloric music in Peru, rap culture in the UK and music in prisons.

\section{References}

Barendregt, Bart and Wim van Zanten. 2002. 'Popular Music in Indonesia since 1998, in Particular Fusion, Indie and Islamic Music on Video Compact Discs and the Internet'. Yearbook for Traditional Music 34: 67-113.

Bigenho, Michelle. 2002. Sounding Indigenous: Authenticity in Bolivian Music Performance. New York: Palgrave Macmillan.

Bigenho, Michelle and Henry Stobart. Forthcoming. 'Grasping Cacophony in Bolivian Heritage Otherwise'. Anthropological Quarterly.

Butterworth, James. 2017. 'The Animador as Ethical Mediator: Stage Talk and Subject Formation at Peruvian Huayno Music Spectacles'. In Collaborative intimacies in music and dance: Anthropologies of sound and movement, edited by Evangelos Chrysagis and Panas Karampampas, 121-38. Oxford: Berghahn Books. 
- 2014. 'The Ethics of Success: Paradoxes of The Suffering Neoliberal Self in the Andean Peruvian Music Industry'. Culture, Theory, and Critique 55(2): 212-32.

Cook, Nicholas. 2000. Analysing musical multimedia. Oxford: Oxford University Press.

Escobar, Arturo. 2001. 'Culture sits in places: reflections on globalism and subaltern strategies of localization'. Political Geography 20(2): 139-74.

Fiol, Stefan. 2010. 'Dual Framing: Locating Authenticities in the Music Videos of Himalayan Possession Rituals'. Ethnomusicology 54(1): 28-53.

Frith, Simon. 1998. Performing rites: On the value of popular music. Cambridge, MA: Harvard University Press.

Gray, Lila Ellen. 2013. Fado Resounding: Affective politics and urban life. Durham and London: Duke University Press.

Gutiérrez Santayana, María T. 1992. Actas y memorias científicas: XI Congreso Nacional de Folklore, I Congreso Internacional Andino de Folklore, 19-23 August 1991, Huancayo, Perú. Huancayo: IRINEA.

Harris, Rachel. 2005. 'Reggae on the silk road: The globalization of Uyghur pop'. China Quarterly 183: 627-43. 
Holt, Fabian. 2007. Genre in popular music. Chicago and London: University of Chicago Press.

International Intellectual Property Alliance. 2010. Special 301 report: Peru. Available from http://www.iipawebsite.com/rbc/2010/2010SPEC301PERU.pdf (last accessed 21 June 2017).

Keil, Charles. 1966. Urban blues. Chicago and London: University of Chicago Press.

Langlois, Tony. 2009. 'Pirates of the Mediterranean: Moroccan music video and technology.' Music, Sound and the Moving Image 3(1): 71-85.

Manuel, Peter. 1991. 'Latin music in the United States: Salsa and the mass media.' Journal of Communication 41(1): 104-16.

Mendoza, Zoila S. 2008. Creating Our Own: Folklore, Performance, and Identity in Cuzco, Peru. Durham and London: Duke University Press.

Morcom, Anna. 2008. 'Getting heard in Tibet: Music, media and markets'. Consumption markets and culture 11(4): 259-85.

_. 2015. 'Landscape, Urbanization, and Capitalist Modernity: Exploring the 'Great Transformation' of Tibet Through its Songs'. Yearbook for Traditional Music 47: 16189. 
Negus, Keith. 1999. Music Genres and Corporate Cultures. London and New York: Routledge.

Ortiz Rescaniere, Alejandro. 2001. La pareja y el mito: estudios sobre las concepciones de la persona y de la pareja en Los Andes. Lima: Pontificia Universidad Católica del Perú, Fondo Editorial.

Romero, Raúl R. 1999. 'De-esencializando al mestizo andino'. In Cultura y globalización, edited by Carlos Iván Degregori and Gonzalo Portocarrero. Lima: Red para el Desarrollo de las Ciencias Sociales del Perú.

- 2001. Debating the Past: Music, Memory, and Identity in the Andes. Oxford: Oxford University Press.

- 2002. 'Popular music and the global city: huayno, chicha, and techno-cumbia in Lima, Peru'. In From Tejano to Tango: Essays on Latin American Popular Music, edited by Walter Clark, 217-39. New York: Routledge.

Solomon, Thomas. 1997. Mountains of Song: Musical Construction of Ecology, Place, and Identity in the Bolivian Andes. Ph.D. Thesis. University of Texas at Austin.

Sparling, Heather. 2008. 'Categorically speaking: towards a theory of (musical) genre in Cape Breton Gaelic culture'. Ethnomusicology 52(3): 401-425. 
Stobart, Henry. 2006a. 'Devils, Daydreams and Desire: Siren Traditions and Musical Creation in the Central-Southern Andes'. In Music of the Sirens, edited by Linda Phyllis Austern and Inna Naroditskaya, 105-139. Bloomington: Indiana University Press.

- 2006b. Music and the Poetics of Production in the Bolivian Andes. Aldershot: Ashgate.

—. 2010. 'Rampant Reproduction and Digital Democracy: Shifting Landscapes of Music Production and "Piracy" in Bolivia'. Ethnomusicology Forum 19(1): 27-56.

_ 2011. 'Constructing community in the digital home studio: Carnival, creativity and indigenous music video production in the Bolivian Andes'. Popular Music 30(2): 209-26.

— 2016 'Dancing in the Fields: Imagined Landscapes and Virtual Locality in Indigenous Andean Music Videos'. TRANS Revista Transcultural de Música 20.

Stromberg, Peter. 2009. Caught in play: How entertainment works on you. Stanford: Stanford University Press.

Taylor, Timothy. 1997. Global Pop: World Music, World Markets. New York: Routledge. is 
Tucker, Joshua. 2013a. 'Producing the Andean Voice: Popular Music, Folkloric Performance, and the Possessive Investment in Indigeneity'. Latin American Music Review 33(2): 31-70.

—. 2013b. Gentleman Troubadours and Andean Pop Stars: Huayno Music, Media Work, and Ethnic Imaginaries in Urban Peru. Chicago and London: University of Chicago Press.

_ 2013c. 'From The World of the Poor to the Beaches of Eisha: Chicha, Cumbia, and the Search for a Popular Subject in Peru'. In Cumbia! Scenes of a Migrant Latin American Music Genre, edited by Héctor Fernández L'Hoeste and Pablo Vila, 138-167. Durham and London: Duke University Press.

Turino, Thomas. 1983. 'The Charango and the "Sirena": Music, Magic, and the Power of Love'. Latin American Music Review 4(1): 81-119.

—. 1988. 'The Music of Andean Migrants in Lima, Peru: Demographics, Social Power, and Style'. Latin American Music Review 9(2): 127-150.

-1993. Moving Away from Silence: Music of the Peruvian Altiplano and the Experience of Urban Migration. Chicago: University of Chicago Press.

Tuohy, Sue. 1999. 'The Social Life of Genre: The Dynamics of Folksong in China'. Asian Music 30(2): 39-86. 
Van Vleet, Krista E. 2008. Performing Kinship: Narrative, Gender, and the Intimacies of Power in the Andes. Austin: University of Texas Press.

Vernallis, Carol. 2004. Experiencing Music Video. New York: Colombia University Press.

Yarupaitán Galván, Genaro, and Joaquina Albán Castillo. 2004. 'Fanerógamas de la provincia de Huancayo, Perú'. Revista Peruana de Biología 11(2): 193-202.

Yúdice, George. 2003. The expediency of culture: Uses of culture in the global era.

Durham and London: Duke University Press.

\section{Discography}

García Zárate, Raúl. 1998. Peru-Guitara. France: ASPIC. Compact Disc.

\section{Figures}

Figure 1. Chicas Dulces del Folklore (Sweet Girls of Folklore), a quartet of santiagueras, performing to camera. Photograph by the author.

Figure 2. Lenin Ramos recording video of Rosmery Perez Inocente (known artistically as Salcahuasinita de Oro [Golden Girl from Salcahuasi]) by a river. Photograph by the author. 